Acknowledgements: We want to thank all the participants of the EIRA study and the clinical collaborators for their valuable contribution. We also want to thank the staff for their dedicated work with the data collection.

Disclosure of Interests: None declared DOI: 10.1136/annrheumdis-2021-eular.2937

\begin{tabular}{|l|l}
\hline POS0485 & TRAJECTORY CLUSTERS OF RADIOGRAPHIC \\
PROGRESSION IN RHEUMATOID ARTHRITIS \\
PATIENTS: ASSOCIATIONS WITH CLINICAL \\
VARIABLES
\end{tabular}

S. Blüml ${ }^{1}$, A. Platzer ${ }^{1}$, F. Alasti ${ }^{1}$, D. Aletaha ${ }^{1}$, J. S. Smolen ${ }^{1}$, H. Radner ${ }^{1}$ ${ }^{1}$ Medical University Vienna, Rheumatology, Wien, Austria

Background: Joint damage is a defining feature of rheumatoid arthritis (RA), a major driver of functional impairment and of reduction of quality of life. Many factors are associated with damage accrual however, the course of structural damage of individual patients over time and factors associated with such trajectories have not been investigated.

Objectives: Identification of trajectories of radiographic damage in RA by clustering patients according to the shape of their curve of Sharp-van der Heijde scores (SHS) over time. Developing models to predict their progression cluster from baseline characteristics.

Methods: Patient-level data over a two-year period from 5 large randomized controlled trials on TNF-inhibitors in RA (ERA, PREMIER, TEMPO, GO-BEFORE and GO-FORWARD) were used. SHSs were clustered in a shape-respecting manner to identify distinct clusters of radiographic progression. Characteristics of patients within different progression clusters were compared at baseline and over time. Logistic regression models were developed to predict trajectory of radiographic progression using information at baseline.

Results: In total 1887 patients with $7738 \mathrm{x}$-rays were used for cluster analyses. We identified 4 distinct clusters with characteristic shapes of radiographic progression: one with a stable SHS over the whole 2-year period ( $\mathrm{CO} /$ lowChange; $86 \%$ ); one with relentless progression (C1/rise; $5.8 \%$ ); one with decreasing SHS (C2/improvement; 6.9\%); and one going up and down (C3/ bothWays; $1.4 \%$ ) of the SHS. Robustness of clusters and shapes of progression over time were confirmed using different clustering methods and cut-offs to define radiographic progression (Figure 1). Regression models identified disease duration, baseline CRP and SHS and treatment status as predictors for cluster assignment (Table 1), showing good performance (PCC 87.5\%; Nagelkerke ${ }^{2}$ 0.36)

Conclusion: We were able to identify 4 different clusters of radiographic progression over time in patients with RA, most remarkably one with relentless progression and another one with amelioration of joint damage over time, suggesting the existence of distinct patterns of joint damage accrual in RA. The nature of the

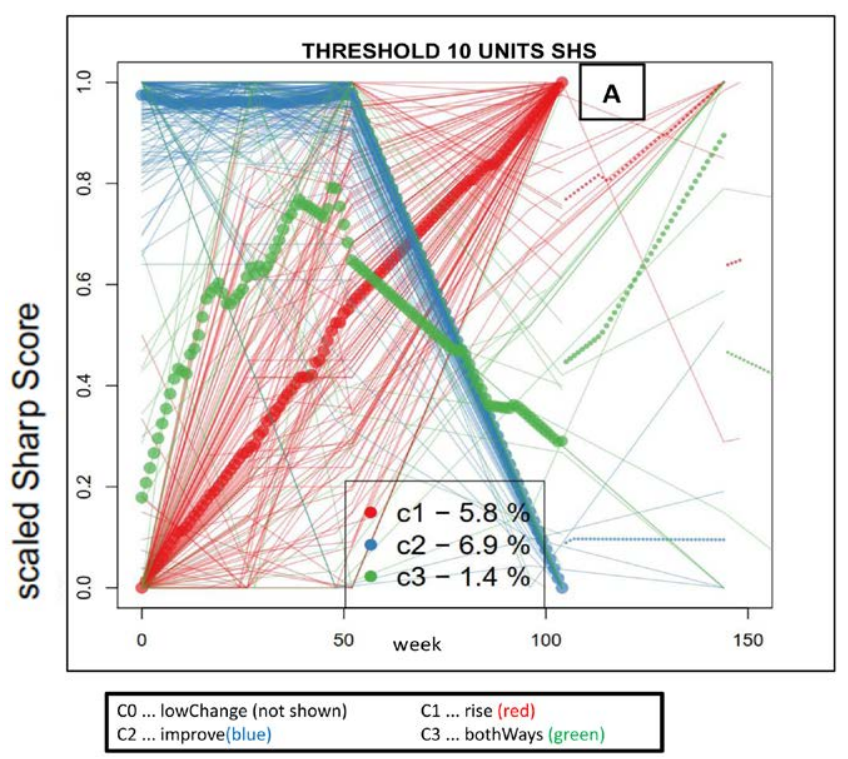

Figure 1. Representations of the major three clusters of radiologic progression curves.(A) shows the curves of all patients with a SHS-range $>=10$, colored by their cluster. Values between visits were linearly interpolated. Big dotted line is the median of particular cluster, thinner lines represent single patient values. Cluster CO llowChange are patients without enough variation in SHS to be seen as a curve, therefor not shown in the diagrams. identified trajectories is mostly explained by inflammatory load, disease duration and especially type of treatment.

Table 1. Simple logistic regression models to predict assignment to clusters of radiologic progression using information at baseline. Variables entered but not selected by a stepwise approach were: rheumatoid factor, age, gender, tender joint count

\begin{tabular}{lllll}
\hline c0/low change vs: & \multicolumn{2}{l}{ C1/rise Cluster } & \multicolumn{2}{l}{ C2/improve Cluster } \\
\hline parameters & OR & $95 \% \mathrm{Cl}$ & OR & $\mathbf{9 5 \%} \mathbf{C l}$ \\
\hline X-ray Score & 1.02 & $1.01-1.03$ & 1.03 & $1.02-1.03$ \\
CRP (mg/dl) & 1.12 & $1.07-1.16$ & 0.98 & $0.90-1.07$ \\
$\begin{array}{l}\text { Duration (years) } \\
\text { Treatment }\end{array}$ & 0.87 & $0.80-0.95$ & 1.09 & $1.05-1.12$ \\
Combination & & & & \\
csDMARD & REF & REF & REF & REF \\
bDMARD Mono & 4.98 & $2.88-8.63$ & 0.05 & $0.01-0.23$ \\
& 2.28 & $1.29-4.04$ & 0.64 & $0.38-1.08$ \\
\hline
\end{tabular}

Disclosure of Interests: Stephan Blüml Speakers bureau: Novartis, MSD Abvie, Pfizer, Consultant of: MSD, Lilly, Novartis, Alexander Platzer: None declared, Farideh Alasti: None declared, Daniel Aletaha Speakers bureau: Abbvie, Amgen, Lilly, Merck, Novartis, Pfizer, Roche, Sandoz, Consultant of: Abbvie, Amgen, Lilly, Merck, Novartis, Pfizer, Roche, Sandoz, Grant/research support from: Abbvie, Amgen, Lilly, Novartis, Roche, SoBi, Sanofi, Josef S. Smolen Speakers bureau: AbbVie, Amgen, AstraZeneca, Astro, Bristol-Myers Squibb, Celgene, Celltrion, Chugai, Gilead, ILTOO Pharma, Janssen, Lilly, Merck Sharp \& Dohme, Novartis-Sandoz, Pfizer, Roche, Samsung, Sanofi, and UCB., Consultant of: AbbVie, Amgen, AstraZeneca, Astro, Bristol-Myers Squibb, Celgene, Celltrion, Chugai, Gilead, ILTOO Pharma, Janssen, Lilly, Merck Sharp \& Dohme, Novartis-Sandoz, Pfizer, Roche, Samsung, Sanofi and UCB., Grant/research support from: Dr Smolen received grants to his institution from Abbvie, AstraZeneca, Janssen, Lilly, Merck Sharpe \& Dohme, Pfizer, and Roche, Helga Radner: None declared

DOI: 10.1136/annrheumdis-2021-eular.2991

\section{POS0486 FACTORS ASSOCIATED WITH CHRONOTROPIC RESPONSE IN PEOPLE WITH RHEUMATOID ARTHRITIS}

A. Osailan ${ }^{1}$ on behalf of Physical activity in Rheumatoid arthritis research team and Research department in Dudley Hospital. ${ }^{1}$ Prince Sattam Bin Abdulaziz University, Health and Rehabilitation Sciences, Alkharj, Saudi Arabia

Background: People with rheumatoid arthritis (RA) are at high risk for cardiovascular diseases (CVD) and CVD mortality. Reduced Chronotropic response (CR), which produces exercise intolerance, is known as a contributing factor to CVD and mortality. Studies have shown that people with RA have reduced CR However, knowledge about the factors associated with CR in people with RA is limited.

Objectives: To explore the factors associated with CR including CVD risk factors, inflammatory markers and cardiorespiratory fitness $\left(\mathrm{VO}_{2}\right.$ peak).

Methods: 106 people with RA completed a treadmill exercise tolerance test while heart rate $(\mathrm{HR})$ was monitored via 12 leads $E C G$. CR was defined as the percentage of [(achieved peak HR minus resting HR) divided by (age-predicted maximum HR minus resting HR)]. Serological CVD risk factors and inflammatory markers including lipids profile, markers of insulin resistance and sensitivity (HOMA, QUICKi), high sensitivity C-reactive protein (hsCRP), erythrocyte sedimentation rate (ESR), fibrinogen and white blood cells (WBC) were examined via a fasted blood sample. $\mathrm{VO}_{2}$ peak was assessed via breath-by-breath gas analysis.

Results: $34 \%$ had reduced CR based on the cut-off value $(\leq 80 \%)$ and the average CR was $86.2 \pm 21 \%$. Body mass index $(r=-0.33, p=.001)$, HOMA ( $r=$ $0.26, p=.009)$, hsCRP $(r=-0.23, p=.02)$, ESR $(r=-0.21, p=.04)$, fibrinogen $(r=-0.2$, $p=.05)$, WBC $(r=-0.21, p=.04)$ were inversely associated with $C R$, whereas, high density lipoprotein $(\mathrm{HDL})(\mathrm{r}=0.43, \mathrm{p}<.001)$, QUICKi $(\mathrm{r}=0.31, \mathrm{p}=.002)$, and $\mathrm{VO}_{2}$ peak $(r=0.4, p<.001)$ were positively associated with $C R$. When all the variables were entered into a stepwise linear regression, $\mathrm{HDL}(\mathrm{p}<.001)$ and $\mathrm{VO}_{2}$ peak $(p=.009)$ were independently associated with $C R$.

Conclusion: The current findings suggest that $\mathrm{CR}$ in RA was associated with many CVD risk factors, inflammatory markers, and cardiorespiratory fitness. Among all the varibales, HDL and cardiorespiratory fitness were moderately and independently associated with CR. Future studies should investigate the effect of improving these associated variables on $\mathrm{CR}$ in people with RA via exercise training programes.

Acknowledgements: Thanks to physical activity in Rheumatoid arthritis research team and Research department in Dudley Hospital. Sincere appreciation and gratitude to Dr Jet Veldhuizen van Zanten, Prof. Joan Duda, and Prof. 